\title{
AVERAGE TOTAL HEMISPHERIC EMISSIVITY MEASUREMENT IN THE LWIR SPECTRUM FOR ADHESIVE TAPES USED IN THE THERMOGRAPHY TAPE TEST
}

\author{
R. P. Mendes ${ }^{\mathrm{a}}$, \\ D. L. F. Pottie ${ }^{a}$, \\ M. Oliveira ${ }^{a}$, \\ L. V. S. Martins ${ }^{\mathrm{b}}$, \\ and R. A. M. Ferreira ${ }^{a}$

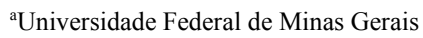 \\ Programa de Pós-graduação em Engenharia \\ Mecânica \\ Av. Antônio Carlos, 6627 \\ CEP. 31270-901, Belo Horizonte, Minas \\ Gerais, Brasil \\ ramondepaoli@yahoo.com.br \\ dpottie@gmail.com \\ maurymoj@gmail.com \\ r.ferreira102@hotmail.com \\ bUniversidade Federal de Minas Gerais \\ Grupo de Refrigeração e Aquecimento \\ Av. Antônio Carlos, 6627 \\ CEP. 31270-901 \\ Belo Horizonte, Minas Gerais, Brasil \\ leo.vsm@hotmail.com \\ Received: May 05, 2020 \\ Revised: May 06, 2020 \\ Accepted: Mar 10, 2021 \\ ABSTRACT
Thermographers often use comparative methods to estimate surface \\ emissivity. Among the most used is the tape method. In this method a known \\ emissivity tape in the LWIR (Long Wavelength Infrared) spectrum is placed \\ on the surface to be inspected. After thermal equilibrium, the temperature of \\ the tape and the surface under inspection must be the same. In this case, the \\ temperature observed on the tape is the reference temperature. The emissivity \\ of the surface must then be changed until the reference temperature is \\ reached. It is common practice to admit the value of the emissivity of the \\ adhesive tape as 0.95 , there are few studies that present these data with \\ metrological rigor, which leads to doubts about the emissivity of the \\ commercial tapes. In this work, experiments were performed on Tekbond, \\ Double A, 3M 101, Rapix, Altape, adhesive tapes for temperatures of 50, 55, \\ 60,65 and $70^{\circ} \mathrm{C}$. An experimental apparatus was developed through which it \\ was possible to estimate surface reflection, transmission and atmospheric \\ emission for one and two layers of tapes, in order to make emissivity \\ measurements possible. Through the data it was possible to statistically \\ estimate the LWIR average total hemispheric emissivity as well as the \\ acceptance range to $95 \%$ certainty, being therefore equal to $\varepsilon=0.94 \pm 0.03$. It \\ is possible to arm, therefore, that the value of 0.95 , usually used as emissivity \\ of the adhesive tape, is extremely reasonable because it is 0.01 of the average \\ value of the Gaussian distribution calculated by this work. \\ Keywords: thermography, tape, test, emissivity
}

\section{NOMENCLATURE}

d Distance from camera to target, $\mathrm{m}$

$\mathrm{E}_{\mathrm{cn}} \quad$ Black body emission

$\mathrm{E}_{\mathrm{cr}} \quad$ Real body emission

$\mathrm{K}_{\mathrm{atm}}$ Damping scale factor of the radiometric signal

$\mathrm{S}$ Total signal arriving on camera, $\mathrm{Wm}^{-2}$

$\mathrm{S}_{\mathrm{ob}} \quad$ Surface emission, $\mathrm{Wm}^{-2}$

$\mathrm{S}_{\text {ref }} \quad$ Reflected signal, $\mathrm{Wm}^{-2}$

$\mathrm{S}_{\mathrm{atm}} \quad$ Atmospheric emission, $\mathrm{Wm}^{-2}$

$\mathrm{T}$ Temperature, $\mathrm{K}$

$\mathrm{T}_{\mathrm{amb}} \quad$ Ambient temperature, $\mathrm{K}$

$\mathrm{T}_{\text {ob }} \quad$ Object temperature, $\mathrm{K}$

$\mathrm{T}_{\text {ref }} \quad$ Reflected temperature, $\mathrm{K}$

\section{Greek symbols}

$\begin{array}{ll}\phi & \text { Azimuth angle } \\ \varepsilon & \text { Emissivity } \\ \tau & \text { Transmissivity } \\ \lambda & \text { Wavelenght, } \mu \mathrm{m} \\ \theta & \text { Zenith angle } \\ \alpha & \text { Absorptivity } \\ \rho & \text { Reflectivity } \\ \omega & \text { Relative humidity of the air } \\ \sigma & \text { Stefan-Boltzmann constant, } \mathrm{Wm}^{-2} \mathrm{~K}^{-4}\end{array}$

\section{Subscripts}

atm atmosphere/atmospheric

ob object 


\section{INTRODUCTION}

In 1800, William Herschel (1800) discovered that the spectrum of sunlight has energy at wavelengths in the infrared range. In 1840, J. F. W. Herschel, son of William Herschel, was able to transcribe on paper an image representative of such wavelengths, originating thermography.

Since its discovery, thermography has been used in the most diverse branches of science. Studies have used thermographic analysis in medical applications (Figueiredo et al., 2018; Barnes, 1963; Tavares et al., 2018; Sousa et al., 2017; Ng, 2009), as a nondestructive test tool (Usamentiaga et. al., 2014; Lizaranzu et al., 2015; Garnier et al., 2011; Almond et al., 2017; Meola et al., 2016; Titman, 2001), in military applications (Zalewski et al. 2017; Neves et al., 2018; Milewski, 2009; Tang et al., 2018), among others.

The thermographic measurement is dependent on parameters such as the distance of the object to be measured from the camera, the signal coming from reflection, the signal coming from atmospheric emission and mainly the value of the object surface emissivity $(\varepsilon)$ to quantify the radiation emitted by the object due to its non-zero temperature.

There are different methods to measure the emissivity of a given surface: Calorimetric method, Optical reflectivity method, Multi-spectral radiation thermometry method and Energy radiation method (He et al., 2009).

There are also authors who divide into only two large groups, radiometric methods and calorimetric methods, without a clear division line between them (Králík, 2016). Radiometric methods measure emitted and/or reflected electromagnetic radiation through a non-contact bolometer sensor, whereas calorimetric methods measure the heat transfer of the object measured when placed inside a cavity in which the exchange of heat by radiation is dominant.

Traditional ways of determining emissivity with the radiometric method include comparing the measurement with a reference temperature, such as that of a blackbody in thermal equilibrium with the surface to be measured (Huilong, 2010) or by simultaneously measuring the surface temperature with a calibrated thermographic camera and highprecision contact temperature sensors, adjusting the emissivity on the thermocouple until the thermocouple reading coincides with that of the thermocouples (Orlando et al., 2009).

A common application of the radiometric method is to cover part of the object surface with an adhesive tape, an adhesive plastic, an ink or other material with high and known emissivity, to determine its emissivity. Adhesive tapes are preferably used for this purpose, by adding small thermal inertia to the assembly, low cost and simplicity. With the use of a calibrated thermographic camera, the surface temperature is measured with the cover in thermal equilibrium and without the cover. The emissivity of the surface without the cover is then calculated so that the two measurements are equal (Silva, 2010).

Technical equipment manuals (CEMIG, 2010; Flir, 2015) recommend the tape emissivity to be assumed as equal to 0.95 . Such value is independent of color, since the analysis is done in the LWIR (Long Wavelength Infrared). Therefore, it is common to assume the emissivity of the tape as this value. However, there are few studies in the literature that prove by statistical approach this value, as well as a comparison between the different brands of adhesive tapes available in the market.

In order to generate more confidence to the thermographers that use the emissivity of the tape equal to 0.95 , this work performs experiments to measure the emissivity of tapes of the brands Tekbond, Doble A, 3M 101, Rapifix and Altape, varying the temperature between 50 and $70^{\circ} \mathrm{C}$ at intervals of $5^{\circ} \mathrm{C}$. The samples of the different manufacturers in the different temperature ranges are measured simultaneously by the thermographic camera and contact temperature sensors, applying the radiometric method in an apparatus assembled exclusively for the experiments.

In the methodology section, is presented the theoretical formulation regarding the operation of thermal camera and the equations used in its operation, as well as the experimental apparatus constructed to provide the necessary data. In the results and conclusion section are presented the measured data as well as the statistical analysis performed, with an acceptance band, the total hemispheric emissivity for a set of adhesive tapes as well as the consideration about its habitual use as 0.95 .

\section{METHODOLOGY}

$$
\mathrm{S}=\mathrm{S}_{\mathrm{ob}}+\mathrm{S}_{\mathrm{refl}}+\mathrm{S}_{\mathrm{atm}}
$$

If the measurand is not a blackbody, unitary emissivity, the signal (S) received by the camera is the sum of the signal from the surface emission $\left(\mathrm{S}_{\mathrm{ob}}\right)$, the atmospheric emission $\left(\mathrm{S}_{\mathrm{atm}}\right)$ and the reflection signal $\left(\mathrm{S}_{\text {refl }}\right)$ as presented in Eq. (1). Figure 1 shows simplified emission, transmission and reflection signals.

According to Chrzanowski (2010), the operation of the camera can be understood in 5 steps: (1) The camera is positioned in relation to the object to be measured; (2) The radiation from the object is refracted through the lens until it reaches internal thermal sensors; (3) the sensors convert thermal energy into a digital signal in a field of $12-16$ binary digits; (4) Processors relate the binary signal with radiation values; (5) Radiation values are converted into temperature scale values as a function of the pixel intensity in an 8-bit image. Figure 2 schematically shows the measurement components used to model the 
reading made by the camera (Minkina and Klecha, 2016).

$$
\mathrm{S}_{\mathrm{atm}}=\varepsilon \mathrm{S}_{\mathrm{atm}} \sigma_{\mathrm{atm}} \mathrm{T}_{\mathrm{amb}}^{4}=\left(1-\tau_{\mathrm{atm}}\right) \sigma \mathrm{T}_{\mathrm{amb}}^{4}
$$

The portion emitted by the atmosphere, in general, has the least influence on the measurement. Considering that the atmosphere emits diffusely, with directional spectral distribution equivalent to a black body at the same temperature, one can calculate that the radiometric signal emitted by the environment is of the form presented in Eq. (2) in which $S_{a t m}$ is the radiometric signal emitted by the atmosphere, $\varepsilon_{a t m}$ is the atmospheric emissivity, $\sigma$ is Stefan-Boltzmann constant equal to $5.67 \cdot 10^{-8} \mathrm{Wm}^{-2} \mathrm{~K}^{-4}, \mathrm{~T}_{\mathrm{amb}}$ is the ambient temperature in $\mathrm{K}$ and $\tau_{\text {atm }}$ is the atmospheric transmissivity.

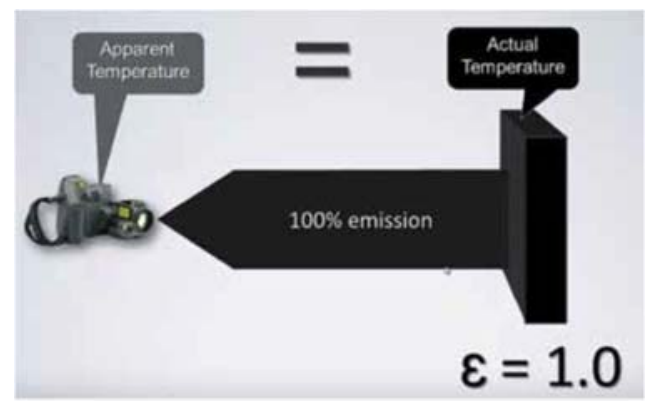

(a) Signal received by thermal camera with unitary emissivity

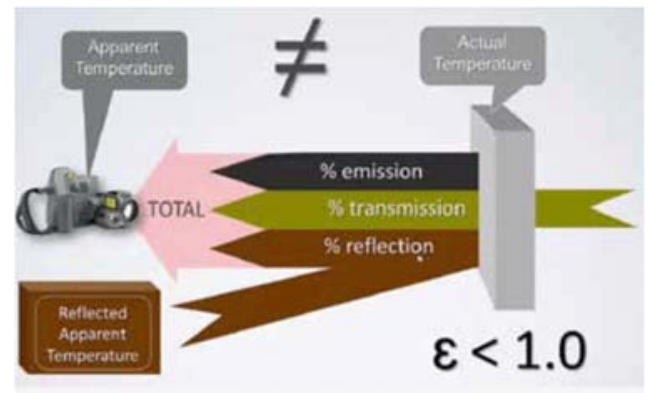

(b) Signal received by thermal camera with emissivity less than one

Figure 1. Influence of emissivity on radiometric signal captured and interpreted by thermal camera (Flir, 2015).

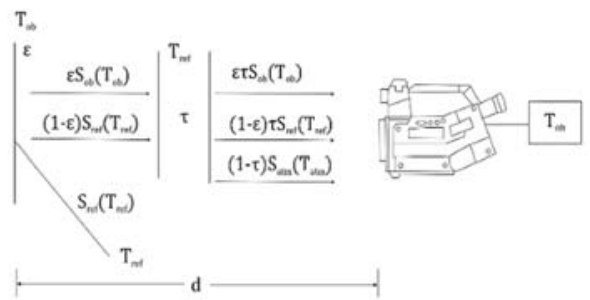

Figure 2. Signal composition received by the Thermocouple (Minkina and Klecha, 2016).

$$
\alpha+\rho+\tau=1
$$

The portion equivalent to the reflected signal consists of the reflection of the radiation coming from the bodies that surround the object being inspected. To quantify it, it is first necessary to characterize the optical properties of the surface. Incropera et. al (2014) define that for any surface, the relation present in Eq. (3) must always be respected.

$$
\rho=1-\varepsilon
$$

In which $\alpha$ is the absorptivity, $\rho$ is the reflectivity and $\tau$ is the transmissivity. Considering a gray $(\alpha=\varepsilon)$ and opaque $(\tau=0)$ surface, it is possible to rearrange Eq. (3) to determine the reflectivity $\rho$ as present in Eq. (4).

$$
\mathrm{S}_{\mathrm{ref}}=\rho_{\mathrm{ob}} \tau_{\mathrm{atm}} \mathrm{T}_{\mathrm{ref}}^{4}=\left(1-\varepsilon_{\mathrm{ob}}\right) \tau_{\mathrm{atm}} \mathrm{T}_{\mathrm{ref}}^{4}
$$

In this way, the reflected radiometric signal $\mathrm{S}_{\mathrm{ref}}$ in $\mathrm{Wm}^{-2}$ can be calculated by Eq. (6).

$$
\mathrm{T}_{\mathrm{ob}}=\sqrt{\frac{\mathrm{S}-\mathrm{S}_{\mathrm{ref}}-\mathrm{S}_{\mathrm{atm}}}{\varepsilon_{\mathrm{ob}} \tau_{\mathrm{atm}} \sigma}}
$$

The portion coming from the object, $\mathrm{S}_{\mathrm{ob}}$ (see Eq. (3)), is determined by the difference between the total signal $\mathrm{S}$ and the reflected signal $\mathrm{S}_{\text {ref }}$ and atmospheric $\mathrm{S}_{\mathrm{atm}}$. Thus, the temperature of the object is defined as a value that satisfies the relation presented in Eq. (6).

$$
\begin{aligned}
& \tau\left(\omega_{\%}, T_{a m b}, d\right)=\begin{array}{l}
K_{a t m} e^{-\sqrt{d}\left[\alpha_{1}+\beta_{1} \sqrt{\omega\left(\omega_{\%}, T_{a m b}\right)}\right]}+ \\
\left(1-K_{a t m}\right) e^{-\sqrt{d}\left[\alpha_{2}+\beta_{2} \sqrt{\omega\left(\omega_{\%}, T_{a m b}\right)}\right]}
\end{array} \\
& \omega\left(\omega_{\%}, T_{a m b}\right)=\frac{\omega_{0} e\left(h_{1}+h_{2} T_{a m b}+h_{3} T_{a m b}^{2}+h_{4} T_{a m b}^{3}\right.}{100}
\end{aligned}
$$

In Eq. (6), the share of atmospheric transmissivity $\tau_{\text {atm }}$ in the LWIR infrared region ( 8 a 14 $\mu \mathrm{m})$ is mainly dependent on the relative humidity $\omega \%$ and the ambient temperature $\mathrm{T}_{\text {atm }}$, and not on the wavelength $\lambda$ (Minkina and Klecha, 2016; Minkina and Klecha, 2015; Baigorria et al., 2004; Singh et al., 2011; Liu et al., 2013). Minkina and Klecha (2015) define the transmissivity $\tau_{\mathrm{atm}}$ in the LWIR region as presented in Eq. (6) in which $\mathrm{K}_{\mathrm{atm}}=1.9$ is a damping scale factor of the radiometric signal, $d$ is the distance, in $\mathrm{m}$, between the thermal imager and the target. The constants $\alpha_{1}, \alpha_{2}, \beta_{1}$ and $\beta_{2}$ are $0.0066,0.0023,0.0126$ and 0.0067 , respectively. Besides that, $\omega \%$ is the 
relative humidity and the constants $\mathrm{h}_{1}=1.5587, \mathrm{~h}_{2}=$ $6.939 \cdot 10^{-2}, \mathrm{~h}_{3}=-2.7816 \cdot 10^{-4}$ and $\mathrm{h} 4=6.8455 \cdot 10^{-7}$.

It is worth mentioning that under calibration conditions, in which the distance between the imager and the target is reasonably small, atmospheric transmissivity $\tau_{\text {atm }}$ approaches the unit. However, for field inspection conditions, at higher distances it is necessary to take into account atmospheric attenuation, defined as $1-\tau_{\text {atm }}$.

In order to calculate the radiometric signal coming from the atmosphere as well as radiometric signal from the reflection, an experimental apparatus was created, represented in Fig. 3.

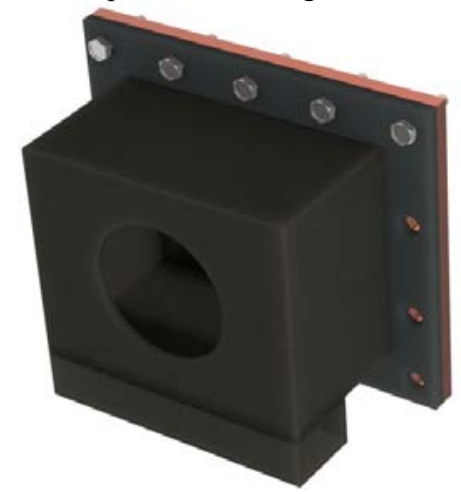

(a) Representation of the experimental apparatus built.

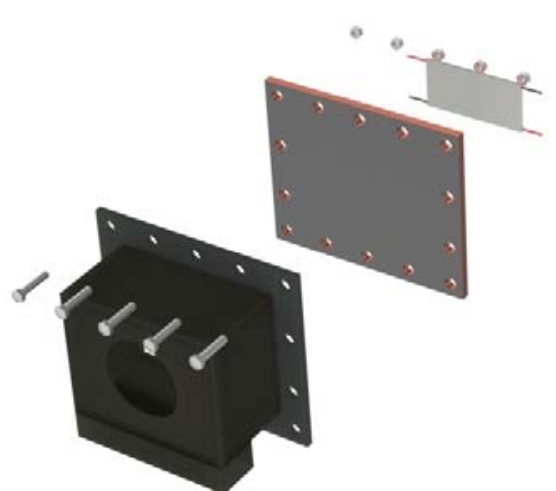

(b) Exploded view of the experimental apparatus constructed, in which it is possible to visualize the components used.

Figure 3. Experimental apparatus constructed.

A closed carbon steel housing was built with a front opening, in which a thermographic window with the dimensions of the lens used in the thermal camera was installed. In addition, the box was painted with black matte paint to mitigate the reflection effects inside. At the back, a copper plate was fixed by means of $14 \mathrm{M} 8 \mathrm{x} 40$ bolts, thus ensuring the seal. Two pellets of effect Peltier Danvic HTC62-30-15.4 (Danvic) were fixed to this copper plate with thermal epoxy resin, to promote the necessary heating to the measurements.

In front of the copper plate, was installed an RTD surface thermistor $\left( \pm 0.5^{\circ} \mathrm{C}\right)$ (Omega, 2009), on which the tape to be measured was fixed. The previously calibrated RTD was connected to an Agilent 34970A data acquisition system (Agilent, 2001) (Fig. 4). A schematic drawing of this mounting is presented in Fig. 5. The heating control of Peltier pellets was done by means of PWM modulation, controlled by a LabView interface and an $\mathrm{H}$ Bridge Motor 30A VNH3SP30 (Microeletronics, 2013).

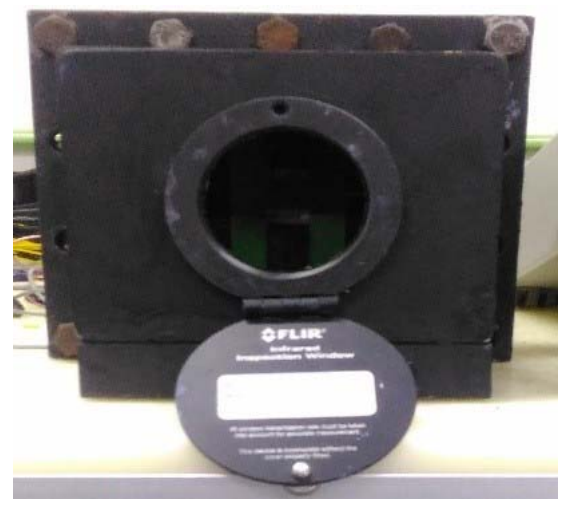

Figure 4. Experimental apparatus built.

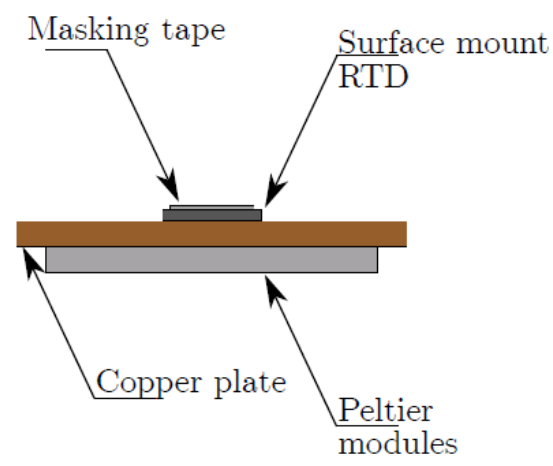

Figure 5. Detail of mounting of pellets, RTD and tape to be studied.

For the determination of the reflected temperature, four T-type thermocouples $\left( \pm 1^{\circ} \mathrm{C}\right)$ were installed on the inner walls of the steel case. The reflected temperature was then obtained from the arithmetic average of the measurements. In addition, a similar thermocouple was positioned inside the housing in order to obtain the ambient temperature. The temperature measurement by thermography was done with a FLIR SC660 thermal camera (Flir, 2010). The uncertainties associated with each measuring element, the measuring mode and the instruments are listed in Tab. 1.

$$
\varepsilon=\frac{\mathrm{E}_{\mathrm{cr}}}{\mathrm{E}_{\mathrm{cn}}}
$$

Observing Eqs. (5) and (6), the importance of correctly quantifying the emissivity of the object $\left(\varepsilon_{\mathrm{ob}}\right)$, 
a parameter of prominence, that directly influences the result obtained by thermographic inspection. Conceptually, the emissivity is defined as the ratio between the amount of energy that a real body emits in the form of radiation at a given temperature $\left(E_{c r}\right)$ by the amount of radiation that a black body would emit at the same temperature $\left(\mathrm{E}_{\mathrm{cn}}\right)$, as presented in Eq. (9) (Incropera et al., 2014).

Table 1. Uncertainties of measurement equipment.

\begin{tabular}{cccc}
\hline Measured Parameter & Measurement Procedure & Measurement Elements & Uncertainty \\
\hline Reflected Temperature & Mean of Internal Wall Temperatures & T-Type Thermocouples & $\left( \pm 1^{\circ} \mathrm{C}\right)$ \\
Temperature & Temperature Measured in Air Inside the Box & T-Type Thermocouples & $\left( \pm 1^{\circ} \mathrm{C}\right)$ \\
Relative Air Humidity & Ambient Air Relative Humidity & Thermohygrometer & $3 \%$ range \\
Object Distance & Measurement & Caliper & 0.0025 \\
Copper Surface Temperature & Temperature Measurement Resistance & Thermal Resistance (RTD) & $\left( \pm 0.5^{\circ} \mathrm{C}\right)$ \\
Adhesive Tape Temperature & Measurement with Thermal camera & Flir SC660 & $\left( \pm 1^{\circ} \mathrm{C}\right)$ \\
\hline
\end{tabular}

$$
\varepsilon(\theta, \phi, \mathrm{T})=\frac{\int_{\lambda=8 \mu \mathrm{m}}^{\lambda=14 \mu \mathrm{m}} \varepsilon_{\lambda}(\theta, \phi, \mathrm{T}) \mathrm{E}_{\lambda}(\mathrm{T}) \mathrm{d} \lambda}{\sigma \mathrm{T}^{4}}
$$

As a rule, emissivity is a surface property that has directional and spectral characteristics. Therefore, the directional emissivity for the LWIR band can be obtained by integrating the values along the entire length of the analyzed infrared, as indicated in Eq. (10) (Howell, 2015).

Considering the surface of the ribbon as di use, the directional emissivity will be equal to hemispherical emissivity, $\varepsilon(\theta, \phi, T)=\varepsilon(\mathrm{T})$, the latter being a function of the surface temperature.

The directional emissivity value for LWIR $\varepsilon(\theta$, $\phi, T)$ is used in the thermal camera to determine the portions reflected and emitted by the object, and therefore small changes in its value can incur considerable measurement errors. For example, if the emissivity value is reported as unitary, the camera will understand that all radiation incident on the sensors is the result of surface emission (Fig. 1(a)) and because of this will give a wrong value for the measured temperature. In this sense, when using the tape test to analyze surface emissivity with thermal cameras, it is necessary that the value commonly used $(0.95)$ is in agreement with the average value presented by the tapes available in the market.

The study used tapes from five different suppliers in order to obtain a representative average result. All measurements were performed in an environment with controlled air temperature and relative humidity and with the use of one and two layers of tapes for comparison purposes.

To satisfy Eq. (6) it was necessary to measure the reflected temperature $\left(\mathrm{T}_{\mathrm{ref}}\right)$, atmospheric temperature $\left(\mathrm{T}_{\mathrm{atm}}\right)$, relative humidity of the air $(\omega)$ and the distance of the measurement object $(d)$. The way of measuring these parameters was explained in the text above and summarized in Tab. 1.

From the pulse width modulation (PWM), the equilibrium temperature of the copper plate, RTD and the test strip was monitored. For such, an interface was developed in the software Labview.

Upon reaching thermal equilibrium, the temperature indicated by the RTD was recorded. Simultaneously, a thermogram was obtained from the interior of the metal case. Later, in the post-processing step of the obtained data, the readings of the thermocouples installed in the walls and of the ambient temperature were inserted in the software FLIR Tools, and the emissivity was adjusted until the temperature of the tape in the thermogram corresponded to the measurement obtained by the contact sensor.

Measurements were performed at 5 temperature levels, $50,55,60,65$ and $70^{\circ} \mathrm{C}$, according to the above procedure. The results were recorded, and then a statistical analysis was done.

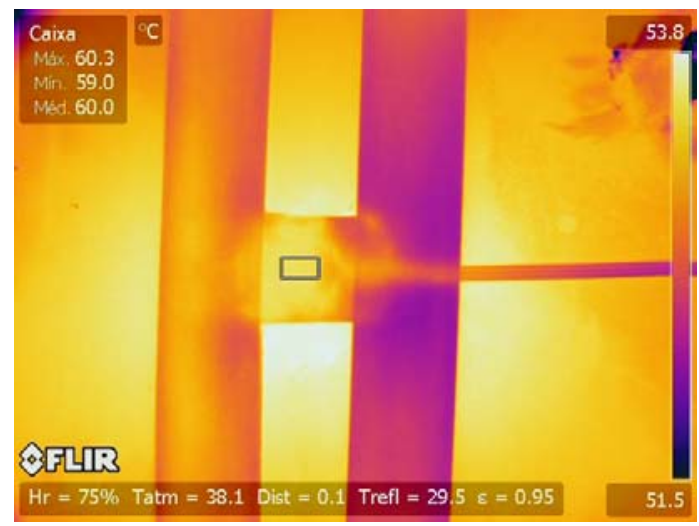

Figure 6. Example of thermography inspection performed at $60^{\circ} \mathrm{C}$ for the tape $3 \mathrm{M} 101$.

\section{RESULTS AND CONCLUSIONS}

Twenty-five thermographic images were generated (as illustrated in Fig. 6), associated with tapes from the five manufacturers and the five temperature points measured by the RTD. Below, as an example, the thermographic image for the tape of the manufacturer $3 \mathrm{M} \mathrm{101}$, at the temperature of $60^{\circ} \mathrm{C}$. 
The values found for average total hemispheric emissivity, as well as the average of each manufacturer are shown in Tab. 2 .

Table 2: Results of measurements of emissivity and average for each manufacturer.

\begin{tabular}{ccccccc}
\hline Manufacturer & $50^{\circ} \mathrm{C}$ & $55^{\circ} \mathrm{C}$ & $60{ }^{\circ} \mathrm{C}$ & $65^{\circ} \mathrm{C}$ & $70{ }^{\circ} \mathrm{C}$ & Avg \\
\hline TEKBOND & 0.92 & 0.92 & 0.93 & 0.93 & 0.94 & 0.93 \\
DOBLE A & 0.96 & 0.96 & 0.96 & 0.96 & 0.96 & 0.96 \\
3M 101 & 0.95 & 0.95 & 0.94 & 0.94 & 0.94 & 0.94 \\
RAPIFIX & 0.94 & 0.93 & 0.93 & 0.92 & 0.92 & 0.93 \\
ALTAPE & 0.94 & 0.93 & 0.93 & 0.92 & 0.92 & 0.93 \\
\hline
\end{tabular}

The camera used was checked in the laboratory, and its systematic error compensated. The data in Tab. 2 presented the following characteristics: (1) Average $=0.937667$; (2) Standard Deviation $=0.013828$; (3) Minimum $=0.92 ;$ (4) Maximum $=0.96 ;(5)$ Variance $=$ 0.000191; (6) Average deviation $=0.011667$; (7) Sample standard deviation $=0.01472$.

The random portion of the error can be calculated by considering a normal distribution around the mean value. Thus, as a function of the standard deviation of the sample presented above and applying the respective student $t$ coefficient to $95 \%$ confidence, it was possible to quantify the Gaussian distribution around the mean value. Being $\varepsilon=0.94 \pm 0.03$.

\section{REFERENCES}

Adam, M., Ng, E. Y. K., Tan, J. H., Heng, M. L., Tong, J. W. K., and Acharya, U. R., 2017, Computer aided diagnosis of diabetic foot using infrared thermography: A review, Computer in Biology and Medicine, Vol. 91, pp. 326-336.

Agilent, 2001, Agilent 34970A Data Aquisition/Switch Unit service guide. https:/www.ke ysight.com/en/pd-1000001313\%3Aep sg\%3Apro-pn34970A/dataacquisition-data-logger-switch-unit?pm $=\mathrm{PL} \&$ nid $=-33261.536881544 \& \mathrm{cc}=$ US\&lc $=$ eng.

Almond, D. P., Angioni, S. L., and Pickering, S. G., 2017, Long pulse excitation thermographic nondestructive evaluation, NDT and E International, Vol. 87, pp. 7-14.

Baigorria, G. A., Villegas, E. B., Trebejo, I., Carlos, J. F., and Quiroz, R., 2004, Atmospheric transmissivity: distribution and empirical estimation around the central Andes, International Journal of Climatology, Vol. 24, No. 9, pp. 1121-1136.

Barnes, R. B., 1963, Thermography of the human body, Science.

CEMIG, 2010, Instrução de execução e critérios para inspeção termográfica em subestações e linhas de transmissão utilizando o termovisor. (in Portuguese)

Chrzanowski, K., 2010, Testing Thermal Imagers, Military University of Technology Warsal.

Danvic, E., Peltier Module HTC62-30-15.4 datasheet, rev.1 ed. http://www.peltier.com.br/files/ dv-62-30.pdf.
Figueiredo, A. A. A., Fernandes, H. C., and Guimaraes, G., 2018, Experimental approach for breast cancer center estimation using infrared thermography, Infrared Physics \& Technology, Vol. 95, pp. 100-112.

Flir, 2010, FLIR SC660 technical specifications, FLIR. http://www.gammadata.se/ assets/Uploads/SC660-specsheet.pdf.

Flir, 2015, Low cost high emissivity materials. https://www.flir.com/discover/rd-science /use-lowcost-materials-to-increase-target-emissivity.

Garnier, C., Pastor, M.-L., F. Eyma, and Lorrain, B., 2011, The detection of aeronautical defects in situ on composite structures using Non-Destructive testing, Composite Structures, Vol. 93, No. 5, pp. 1328-1336.

He, X., Li, Y., Wang, L., Sun, Y., and Zhang, S., 2009, High emissivity coatings for high temperature application: Progress and prospect, Thin Solid Films, Vol 517, No 17, pp. 5120-5129.

Herschel, W., 1800, Investigation of the powers of the prismatic colours to heat and illuminate objects; with remarks, that prove the different refrangibility of radiant heat. to which is added, an inquiry into the method of viewing the sun advantageously, with telescopes of large apertures and high magnifying powers, Phil. Trans. Roy. Soc.

Howell, J., Menguc, M., and Siegel, R., 2015, Thermal Radiation Heat Transfer, CRC Press.

Huilong, M., 2010, Thermal modeling of shape memory alloys wire actuators for automotive applications, Master's thesis, University of Waterloo, Ontario, Canada.

Incropera, F. P., DeWitt, D. P., Bergman, T. L., Lavine, A. S., 2014, Fundamentals of heat and mass transfer, LTC.

Králík, T., Musilová, V., Hanzelka, P., and Frolec, J., 2016, Method for measurement of emissivity and absorptivity of highly reflective surfaces from $20 \mathrm{k}$ to room temperatures, Metrologia, Vol. 53, No 2, pp. 743-753.

Liu, T., Kinouchi, T., and Ledezma, F., 2013, Spatial distribution of glacier melt deduced from solar radiation mapping with refined atmospheric parameters, Journal of Japan Society of Civil Engineers, Ser. B1(Hydraulic Engineering), Vol. 69, No. 4, pp. 181-186.

Lizaranzu, M., Lario, A., Chiminelli, A., and Amenabar, I., 2015, Non-destructive testing of composite materials by means of active thermography-based tools, Infrared Physics \& Technology, Vol. 71, pp. 113-120.

Meola, C., Boccardi, S., Carlomagno, G., Boffa, N., Ricci, F., Simeoli, G., and Russo, P., 2016, Impact damaging of composites through online monitoring and non-destructive evaluation with infrared thermography, NDT\&E International, Vol. 85, pp. 3442. 
Microeletronics, ST, 2013, VNH3SP30-E Datasheet ST Microeletronics, 8 ed. https://www. pololu.com/file/0J51/vnh3sp30.pdf.

Milewski, S., 2009, Fundamental limitations to infrared sensor performance in maritime conditions, in: III International Scientific and Technical Conference Marine Technology and Arms NATCon, Gdynia. (in polish)

Minkina, W., and Klecha, D., 2015, Modeling of atmospheric transmission coefficient in infrared for thermovision measurements, in: AMA Conferences Sensor, Nuremberg Exhibition Centre, Germany, pp. 903-907.

Minkina, W., and Klecha, D., 2016, Atmospheric transmission coefficient modelling in the infrared for thermovision measurements, Journal of sensors and sensor systems, Vol. 5, pp. 17-23.

Neves, E. B., Salamunes, A. C. C., and Stadnik, A. M. W., 2018, Mathematical model for body fat percentage in military using thermal imaging and circumferences, in: 40th Annual International Conference of the IEEE Engineering in Medicine and Biology Society (EMBC), pp. 790-793.

$\mathrm{Ng}$, E. Y. K., 2009, A review of thermography as promising non-invasive detection modality for breast tumor, International Journal of Thermal Sciences, Vol. 48, No. 5, pp. 849-859.

Omega, 2009, Surface Mount RTD Temperature Sensors user guide. USA. https:// www.omega.com/Manuals/manualpdf/M1620.pdf.

Orlando, A. F., Bellido, M. M. H., Santos, P. R. F., and Teixeira, R. N., 2009, Capacitação metrológica em termografia para planejamento de manutenção, in: $V$ Congresso de Inovação Tecnológica em Energia Elétrica (V CITENEL), Belém, PA. (in Portuguese)

Silva, T. C. da, 2010, Concepção, projeto, construção e teste de um aparato experimental para medição de emissividade de ligas com memória de forma, Master's thesis, Faculdade de Tecnologia, Universidade de Brasília, Brasília, Brazil. (in Portuguese)

Singh, J., Bhattacharya, B. K., Kumar, M., and Mallick, K., 2013, Modelling monthly diffuse solar radiation fraction and its validity over the Indian subtropics, International Journal of Climatology, Vol. 33, No. 1, pp. 77-86.

Sousa, E., Vardasca, R., Teixeira, S., Seixas, A., Mendes, J., and Costa-Ferreira, A., 2017, A review on the application of medical infrared thermal imaging in hands, Infrared Physics \& Technology, Vol. 85, pp. 315-323.

Tang, R., Zhang, T., Chen, Y., Liang, H., Li, B., and Zhou, Z., 2018, Infrared thermography approach for effective shielding area of field smoke based on background subtraction and transmittance interpolation, Sensors, Vol 18, No 5, pp. 1450.

Tavares, I., Vardasca, R., Cera, N., Pereira, R., Nimbi, F. M., Lisy, D., Janssen, E., and Nobre, P. J., 2018, A review of infrared thermography as applied to human sexual psychophysiology, International Journal of Psychophysiology, Vol. 133, pp. 28-40.

Titman, D., 2001, Applications of thermography in nondestructive testing of structures, NDT\&E International, Vol. 34, No 2, pp. 149-154.

Usamentiaga, R., Venegas, P., Guerediaga, J., Vega, L., Molleda, J., and Bulnes, F. G., 2014, Infrared thermography for temperature measurement and nondestructive testing, Sensors, Vol. 14, No. 7, pp. 12305 12348.

Zalewski, J., Milewski, S., and Zablotny, M., 2017, Assessment of possibilities to use thermal imaging cameras for air traffic control, Polish Naval Academy, Vol. 24, pp. 193-206. 